\title{
Análise da viabilidade da logística reversa na cidade de Brejo Santo (CE): uma pesquisa de opinião segundo populares
}

Com o surgimento de novas concepções sobre a exploração de recursos materiais e da reutilização de itens já existentes, a sociedade e as entidades governamentais começam a atuar de forma a estimular e cobrar das empresas que esses venham a trabalhar de forma sustentável, sendo que, dessa maneira, as organizações passarão a fazer uso da logística reversa a seu favor, como uma forma de proporcionar ao cliente satisfação e qualidade. O presente estudo objetivou realizar uma pesquisa de opinião acerca da Logística Reversa de acordo com as ideias e concepções dos cidadãos que residem na cidade de Brejo Santo (CE). O estudo foi uma pesquisa de opinião, na qual foi aplicado um questionário cuja amostra foi não probabilística por conveniência. Como resultado, observou-se que a logística reversa se tornou uma ideia bastante difundida no meio da sociedade moderna, ganhando cada vez mais destaque entre as novas concepções acerca do consumo inteligente. Uma das respostas obtidas no presente estudo foi o fato de esse trabalhar a reeducação referente a esse tema e incentivar a sociedade em geral a direcionar o seu olhar para práticas de sustentabilidade e preservação ambiental.

Palavras-chave: Logística Reversa; Resíduos Sólidos; Populares.

\section{Feasibility analysis of reverse logistics in the city of Brejo Santo (CE): a popular opinion poll}

\begin{abstract}
With the emergence of new conceptions about the exploitation of material resources and the reuse of existing items, society and government entities begin to act in a way that encourages and demands that companies work in a sustainable manner. In this way, organizations will use reverse logistics in their favor as a way of providing customer satisfaction and quality. This study aimed to conduct an opinion poll about Reverse Logistics according to the ideas and conceptions of citizens living in the city of Brejo Santo (CE). The study was an opinion poll, in which a questionnaire was applied whose sample was not probabilistic for convenience. As a result, it has been observed that reverse logistics has become a widespread idea in the midst of modern society, gaining increasing prominence among new conceptions of smart consumption. One of the answers obtained in this study was the fact that this work reeducation related to this theme and encourage society in general to direct their gaze to practices of sustainability and environmental preservation.
\end{abstract}

Keywords: Reverse logistic; Solid waste; Popular.

Topic: Sistemas Logísticos

Reviewed anonymously in the process of blind peer
Received: 10/04/2019

Approved: 14/06/2019
Maria Socorro Dias Cardoso

Centro Universitário Dr. Leão Sampaio, Brasil http://lattes.cnpq.br/5358131705389110 maryds 11@hotmail.com

Alyne Leite de Oliveira

Centro Universitário Dr. Leão Sampaio, Brasil

http://lattes.cnpq.br/2112616885682866

alyneoliveira@leaosampaio.edu.br
Referencing this:

CARDOSO, M. S. D.; OLIVEIRA, A. L.. Análise da viabilidade da logística reversa na cidade de Brejo Santo (CE): uma pesquisa de opinião segundo populares. Revista Brasileira de Administração Científica, v.10, n.2, p.109-124, 2019. DOI: http://doi.org/10.6008/CBPC2179684X.2019.002.0008 


\section{INTRODUÇÃO}

A Logística Reversa é tida como uma das áreas que diz respeito a logística empresarial, ela sendo responsabilizada por inúmeras ações, dentre elas, o planejamento, operação e controle de fluxos reversos de natureza diversa, colocando-se em um contexto satisfatório de inúmeros interesses estratégicos. Suas estratégias de produtividade, almejam situações benéficas que trarão satisfação a diferentes eixos empresariais. Diferentes estímulos realizam ações ou, porventura, reações estratégicas as quais as empresas planejam, essas podem sofrer variações dependendo do setor ou do ambiente empresarial, objetivando com isso orientar logisticamente os movimentos de retorno, produtos e satisfação de variados agentes interessados (ALMEIDA, 2012).

A logística reversa atualmente vem despertando interesse de diversos públicos na área acadêmica e principalmente empresarial. Volumes transacionais, a marcante variabilidade de produtos, diminuição do ciclo de vida dos produtos, surgimento de novas legislações ambientais, diferenciação entre as empresas e satisfação de variados interesses acabam atuando como justificativa para que as empresas optem por produções pautadas pelo interesse em fazer com que mercadorias não consumidas e até mesmo as que já foram consumidas, recebam um tratamento que recupere o valor de alguma natureza (LEITE, 2012).

A globalização mundial permitiu o desenvolvimento da logística, onde foi possível observar que todos os setores empresariais se voltassem para outras possibilidades de mercados como maneira estratégica competitiva. Além de todas as modificações que ela permitiu, as necessidades do mercado econômico sofreram grandes mudanças, dessa forma, acarretando uma elevação da demanda de produtos ofertados no meio. O consumidor também vivenciou transformações significativas devido a essa globalização e o surgimento de novas tecnologias, os produtos acabam sofrendo alterações bruscas de maneira que possam vir a acompanhar esse processo constante de modificações em um curto período (MENDONÇA et al., 2017).

Como surgimento dessas novas concepções de mundo, no que concerne à exploração de recursos materiais e da reutilização de itens já existentes, a sociedade e as entidades governamentais começam a atuar de forma a estimular e cobrar das empresas e centros industriais que esses venham a trabalhar de forma sustentável, sendo que dessa maneira as organizações passaram a fazer uso da logística reversa a seu favor, como um forma de proporcionar ao cliente satisfação e qualidade, aumentando a vantagem competitiva estabelecida entre os mercados (SOUZA, 2018).

A atenção voltada a questões ambientais e a competitividade empresarial se voltam aos esforços de uma logística reversa direcionada a promoção ou a criação de valor dos produtos consumidos ou que ainda serão consumidos. Partindo dessas concepções, a prática da logística é entendida como uma maneira de criação de valor empresarial, sendo voltada ou motivada por diversos percalços estratégico (MAURER, 2013).

Diante desses conceitos, o presente estudo objetivou verificar a percepção da população quanto a logística reversa do resíduo oriundo do uso doméstico. Tendo como principais objetivos específicos analisar a maneira como as pessoas realizam o descarte do lixo, observar o que os cidadãos pensam sobre a destinação correta dos resíduos sólidos produzidos, e descrever o que eles vivenciam acerca de logística 
reversa e destinação correta dos resíduos sólidos. A produção dessa pesquisa foi motivada pela necessidade de se compreender a importância do descarte e reutilização adequada dos resíduos produzidos pelos moradores da região estudada bem como a intenção de promover uma reeducação acerca desses questionamentos. É notório relatar a importância de estudos como esse pois, atuam de forma a produzir novos conhecimentos bem como atuar de maneira a conscientizar a sociedade acerca dessa temática.

As principais hipóteses abordadas no estudo foram: a logística reversa é importante para a destinação correta dos resíduos sólidos produzido pela sociedade; as pessoas possuem conhecimento acerca da logística reversa e como a mesma ocorre na cidade. A logística reversa promove a criação de valor dos produtos consumidos ou que ainda serão consumidos.

\section{REVISÃO TEÓRICA}

\section{Logística Reversa}

Atualmente, boa parte das preocupações relacionadas as questões ambientais estão diretamente relacionadas ao processo de desenvolvimento das cidades e de sua urbanização. Antes grande parte dos indivíduos residiam na zona rural e viviam basicamente da prática da agricultura. Com o surgimento de mudanças nesse setor, o indivíduo passará a buscar melhores condições e migraram para os centros urbanos; a partir daí, então, a cidade começa um desenvolvimento desenfreado, e consequentemente, o consumo e a produção de produtos de consumo passam a ser uma das principais características associadas ao consumismo (MENDONÇA et al., 2017)

O crescimento populacional nas cidades associadas ao elevado consumo traz ao dia a dia do homem moderno os desafios de enfrentamento a alta produção de resíduos sólidos e seu descarte adequado. Como uma maneira de tornar realidade práticas sustentáveis aos descartes desses materiais, surge aí a Logística Reversa. A Logística Reversa traz a possibilidade de que os materiais produzidos pelo homem, e após seu consumo, devem receber um destino adequado para que não venha a causar prejuízos ao meio ambiente. Sendo que é de fundamental importância a organização desse fluxo de consumo e descarte através do uso da logística reversa (ISIDRO, 2013).

Trazendo essas concepções para uma visão ambientalista, a realização da prática da logística reversa tem como principal intuito evitar que todos os materiais e bens produzidos que já foram utilizados sejam reinseridos na natureza, como destinação final. Para a sociedade quanto mais indivíduos e entidades tiverem envolvidos nessa causa, maiores serão as preocupações acerca da redução a deposição errônea dos resíduos sólidos e consequentemente haverá possibilidades de manter os recursos ambientais preservados para as próximas gerações (SOUZA, 2018).

Destaca-se que, a partir do momento que a logística reversa foi incorporada no ambiente organizacional, em meados de 1970 por Zikmund e Stanton, a mesma tem tido bastante aceitabilidade nos estudos que estejam relacionados empresas, ambiente natural e possivelmente pode ser correlacionado também as questões de negócios (PEREIRA et al., 2012). 


\section{Conceito e Importância}

A Logística Reversa (LR), em sentido amplo, traz uma abordagem que está relacionada as diversas atividades que fazem ações direcionadas a reutilização de materiais e produtos, perfazendo ações como coleta, desmonte e processamento de bens e produtos objetivados; com isso, a recuperação desses para que possam ser incorporados novamente ao ambiente, dessa forma promovendo uma recuperação sustentável (SOUZA, 2018). Historicamente falando, essa foi relacionada com ações de reciclagem de produtos e questões ambientais assim, ganhou importância em setores como empresas justamente pelo fato da pressão exercida pelos stakeholders correlacionados aos questionamentos ambientais e não podiam passar despercebidos (SHIBAO, 2010).

Relatando de forma mais prática, o termo Logístico Reverso (LR) objetiva a redução da poluição ambiental bem como os desperdícios de tudo aquilo que foi produzido pelo homem moderno, assim como o reuso e reciclagem de materiais. Como exemplo dessa, pode ser citado os supermercados, indústrias e lojas que produzem enormes quantidades de materiais que podem passar pelo processo de reciclagem, esses compreendem os papeis, papelão, restos de madeiras, materiais plásticos entre outros itens que porventura após o seu uso podem ser reutilizados ou reciclados.

\section{Canais Reversos e Gestão de Resíduos Sólidos}

Os Canais reversos de materiais de consumo pode ser entendido como uma forma de fazer com que esses produtos recebam destinação final correta bem como podendo se constituir de produtos que ainda não foram utilizados, que são chamados de pós-venda, ou de produtos usados denominados dessa forma de pós-consumo (LEITE, 2009). As gestões de resíduos sólidos compreendem um conjunto de medidas direcionadas ao manejo e descarte adequado de todo resíduo que é produzido pelo homem. A gestão realizada de forma integrada acaba englobando a participação do órgão federado, tais como governos federal, estaduais e municipais e esses devem atuar diante de questões relacionadas a coleta seletiva, promoção da reciclagem do lixo, inclusão social bem como participação ativa da sociedade (LEITE, 2009).

Esse tipo de gestão inclui a criação de ações direcionadas ao tratamento de questões relacionadas a tomada de decisões acerca dos resíduos sólidos, inclusive do plano nacional, estadual, regionais, municipais e de gerenciamento como um todo, esse deve ainda englobar os resíduos que são produzidos pelos serviços de saúde, construção civil, mineração, industriais, portos e fronteiras etc. (BRASIL, 2016).

\section{Pós-venda}

É uma área de atuação da logística que tem por função realizar o manuseio e equacionamento do fluxo físico e das informações acerca da logística de bens de pós-venda em utilização ou em pouco uso, os quais por diferentes razões acabam retornando aos estágios das cadeias de distribuição direta. $\mathrm{O}$ objetivo desse tipo de logística é fazer agregação de valores a um produto que foi produzido por questões comerciais, alterações do processo dos pedidos, garantias fornecidas pelo fabricante, além de possíveis defeitos ou falhas 
de funcionamento, avarias no transporte (SOUZA, 2018). Os canais reversos de pós-venda são produzidos diferentes formas, para que haja o retorno de boa parte dos produtos com pouco ou nenhum uso, que acabam fluindo no sentido inverso do consumidor ao varejista ao fabricante, entre as empresas e retornando ao ciclo empresarial de alguma forma (SOUZA, 2018).

\section{Pós-Consumo}

É uma área de atividade da logística que operacionaliza o fluxo físico e os conceitos correspondentes aos bens de consumo que são descartados pela sociedade e que acabam retornando ao ciclo de negócios ou ao caminho produtivo através de veículos de distribuição reversos diferenciados. Os bens de consumo são materiais cuja vida útil foi finalizada, ou bens usados de forma a se repensar sobre a reutilização do mesmo (DIAS, 2009).

A logística objetiva adicionar valor a um produto Logístico que é constituído por materiais sem interesse de uso ao proprietário que deu origem ao mesmo o que ainda podem ter características e uso, por materiais descartados no final de sua vida útil e por produtos industriais. Após o consumo, os resíduos podem receber diferentes tipos de destinação, as principais delas são reciclagem, reutilização e redução e todo material que é produzido pelo homem e que acaba poluindo o meio ambiente (ALMEIDA, 2012).

\section{Reciclagem}

Consiste no mecanismo no qual os produtos produzidos são reinseridos ao ciclo de consumo evitando desta forma a retirada de forma excessiva de matérias-primas da natureza e consequentemente agressões ambientais. A diferença entre reciclar e reutilizar consiste no fato de que a reciclagem tem como principal característica o retorno dos materiais que foram utilizados pelo homem de volta à sua origem ou a indústria para que possam passar por novos processos industriais e voltarem a cadeia de consumo (ALMEIDA, 2012; KRUPP, 2017).

Ressalta-se que é de suma importância a reciclagem, essa seria uma forma de reutilizar os bens de consumo e reduzir o uso da matéria prima utilizada para sua produção. Destaca-se, ainda, que que esses recursos utilizados para a produção de bens de consumo são extraídos de matérias-primas do ambiente natural existindo dessa forma fluxo contínuo de transporte de materiais do campo para as cidades. Ressaltase que depois que são usados e que venham a ser descartados no ambiente, esses acabam se acumulando e muitas vezes contaminando o meio ambiente e principalmente os lençóis freáticos (KRUPP, 2017).

Partindo desses conceitos, reforça-se o papel fundamental da reciclagem de resíduos sólidos produzidos pelo homem, esses resíduos quando recebem uma destinação correta contribuem na preservação do meio ambiente, além de diminuir a extração dos recursos da natureza e estimulando a redução do acúmulo de resíduos na zona urbana (SHIBAO, 2010). 


\section{Reutilizar}

A reutilização dos produtos consumidos vem aumentar a vida útil deles, conferindo-lhes reparabilidade, ou seja, o produto volta a ser inserido na cadeia de consumo, e esse passa a ter uma nova personalidade, e uma nova vida. Segundo alguns estudos, os materiais produzidos pelo homem, quando acabam o ciclo de vida útil geralmente eles são eliminados, mas alguns produtos possuem a característica da reutilização e podem ser reinseridos na cadeia de consumo de forma a minimizar os efeitos provocados pelo acúmulo de lixo no meio ambiente. A reutilização desses objetos favorece a política da reciclagem e do reuso de forma a contribuir para o equilíbrio ambiental (GONÇALVES, 2011).

A reutilização de materiais que passaram pelo processo da reciclagem vem contribuir para que haja a diminuição do uso de energia e água e consequentemente da geração de lixo e da produção exacerbada de resíduos sólidos. Reduzir consiste em diminuir o consumo e optar por reutilizar materiais que possivelmente foram reciclados (GONÇALVES, 2011).

\section{Desmanche}

O desmanche consiste na desmontagem de materiais de bens de pós-consumo, e dessa forma são novamente reinseridos na cadeia de uso para que possam ser reaproveitados. O desmanche pode ser encarado como uma forma de valorizar o produto durável que após passar pela coleta, deverá sofrer um processo industrial de desmontagem nos quais suas peças em condições de uso são selecionadas de partes para os quais não haja mais condições de revalorizar o mesmo, mas que eventualmente podem ser reutilizados mediante reciclagem industrial. Ressalta-se que esse mecanismo geralmente está associado a bens duráveis tais como veículos, e máquinas. É, portanto, uma atividade de bastante lucratividade e muito explorada por microempreendedores (PORTOGENTE, 2016).

Os canais de distribuição reversos, são os grandes responsáveis por trazer de volta ao consumo os bens que já tiveram seu ciclo de vida concluído, dessa forma impedindo o acúmulo de resíduos sólidos descartados nomeio ambiente. Os produtos ou matérias advindas dos pós -consumo se acumular nos solos resultados em problemas ambientais, caso não recebam destinação correta e nem retornem ao ciclo de produtividade (PORTOGENTE, 2016).

\section{Política Nacional de Resíduos Sólidos (PNRS)}

A Política Nacional de Resíduos Sólidos (PNRS) é uma lei brasileira (Lei no 12.305/10), e que objetiva ministrar a maneira como o país lida com os resíduos sólidos produzidos pela sociedade brasileira, exigindo, para isso, que transparência por parte dos setores públicos e privados quanto ao gerenciamento desses resíduos. Essa lei dispõe acerca dos princípios, metas e procedimentos, bem como diretrizes que sejam referentes a gestão de forma integrada desses resíduos (KRUPP, 2017). Nos anos de 2014 essa havia determinado que haveria necessidade de abolir lixões e substitui-los por aterros sanitário. Essa foi uma 
decisão geral que objetivava destinação correta para todo o lixo produzido pelas cidades bem como a destinação dos espaços adequados a acomodação desses materiais (KRUPP, 2017).

Como advento dessa lei, o órgão competente deveria assumir suas responsabilidades pela gestão dos resíduos sólidos urbanos, partindo do pressuposto de que com o desenvolvimento das cidades, favoreceu o aumento de produção de resíduos e esses foram se acumulando no ambiente exigindo dessa forma respostas imediatas neste setor. Propostas tais como valorização da coleta seletiva e dos catadores e cooperativas, logística reversa pelas empresas, e uso de compostagem todos esses devem ser visto de forma conjunta, onde cada um terá a sua funcionalidade nesse ciclo de consumo e pós-consumo (ISIDRO, 2013).

\section{Sustentabilidade}

A palavra sustentabilidade corresponde a atividades direcionadas ao desenvolvimento sustentável, e pode ser entendida como ações que atua der forma a não comprometer os recursos naturais e o ambiente para as gerações futuras. A mesma fundamenta-se na junção de questões sociais, ambientais e até mesmo econômicos, sendo ainda considerada como algo que melhora as condições de vida em relação ao uso dos recursos naturais e a maneira correta de utilizá-los, objetivando, com isso, diminuir os impactos causados pela ação do homem moderno de forma resumida seria a harmonização de setores como desenvolvimento econômico e preservação do ambiente natural (GUARNIERI, 2011).

É importante frisar que desenvolvimento sustentável seria uma forma de alertar a sociedade acerca da importância da preservação ambiental, dessa forma mantendo uma produção eficiente de materiais de maneira responsável. Destaca-se que, nos últimos anos, os problemas relacionados a poluição ambiental, as atividades industriais bem como a ação desenfreada do homem para fazer crescer os setores da economia fizeram com que houvesse o despertar para esses questionamentos e termos como responsabilidade social e empresarial tem sido bastante discutido (GUARNIERI, 2011). O consumismo existente fez com que o planeta demonstrasse sinais de que já não suporta o ritmo de consumo desenfreado do homem do século 21 bem como as alterações ambientais por ele provocados (KRUPP, 2017).

\section{Responsabilidade social}

Quando se fala em responsabilidade social, está se referindo ao fato das empresas de maneira voluntaria adotar medidas e ações que atuam promovendo o em estar de seus consumidores internos e externos. Há diversos fatores que dão origem ao conceito de responsabilidade social, quando se menciona o contexto globalização e das alterações industriais, apareceram novas preocupações e expectativas da sociedade, dos consumidores, entre outros (ALMEIDA, 2012; KRUPP, 2017). Como tempo essas ideias deram origem a diversas variantes desse conceito usados para definir responsabilidade social (RS), com destaque para eles Responsabilidade Social Corporativa (RSC), Responsabilidade Social Empresarial (RSE) e Responsabilidade Social e Ambiental (RSA) (EON, 2014). 


\section{Responsabilidade Social Corporativa}

Grupo de atividades que atuam de forma a beneficiar a sociedade e que levam consideração questões como a economia, educação, meio-ambiente, saúde, etc.. Nesses é comum a criação de programas de cunho social, e dessa forma acabam por trazer diversos benefícios entre empresas e comunidade (EON, 2014). De acordo com os conceitos de McWillians et al. (2002),

[...] a responsabilidade corporativa como uma estratégia de diferenciação, é usada para criar novas demandas e obter um preço Premium para um produto ou serviço existente. Ainda segundo os autores, alguns consumidores querem que os produtos que compram apresentem alguns atributos de responsabilidade social (inovação de produtos). Outros consumidores valorizam produtos que são produzidos de forma responsável (inovação de processo).

Já para o pesquisador Porter (1986), essa estratégia consiste em basicamente desenvolver as atividades de uma empresa, buscando agregar valor aos seus produtos e serviços. Dessa forma, a empresa desenvolve uma oferta única no âmbito de todo o mercado, oferecendo produtos e serviços com atributos distintos e valorizados pelos clientes.

Responsabilidade Social Corporativa é uma forma que as empresas adquirem para que possam promover um comportamento ético diante dos materiais de consumo que são produtos pelos mesmos e disponibilizados para a sociedade, dessa forma contribuem de maneira significativa para o desenvolvimento econômico e atuam de maneira a promover a qualidade dos serviços ofertados como um todo.

\section{Responsabilidade Social Empresarial}

Está relacionada a gestão de forma ética e limpa que a empresa tem com as partes que estão interessadas. Dessa forma atuam de maneira a minimizar os impactos ruins no ambiente natural bem como na comunidade (EON, 2014). O termo responsabilidade social empresarial é dinâmico e complexo, admitindo diferentes significados de acordo com os diversos contextos na qual estão relacionados.

A responsabilidade social empresarial está relacionada à responsabilidade de forma legal, para outros podem representar uma maneira ética de agir ante a diferentes contextos relacionados à sociedade englobando toda a cadeia produtiva e o ciclo de vida dos produtos que são consumidos por eles. Ressalta-se que a responsabilidade social corporativa é direcionada as diversas exigências e demandas da sociedade tais como, relação entre clientes e fornecedores, produção com qualidade, satisfação dos clientes, investimentos e pesquisas de alta tecnologia, preservação ambiental entre outros (ALMEIDA, 2012).

No sentido mais amplo a responsabilidade social pode ser encarada como o compromisso e a forma de promover uma contribuição para que o desenvolvimento econômico aconteça de forma sustentável, levando-se em conta que o trabalho desenvolvido deve ser realizado em conjunto com o empregado, familiares, comunidade, sociedade em geral para que haja qualidade vida para empresas e a sociedade em geral (BERTONCELLO et al., 2014). 


\section{Responsabilidade Social e Ambiental}

Atividades realizadas pelas empresas que visam a preservação ambiental. Elas promovem a criação de políticas relacionadas as questões Ambientais objetivando com isso o estímulo a sustentabilidade (EON, 2014). É importante que se relate, que a responsabilidade socioambiental é algo que deve ser encarado como uma forma de ver na produção industrial a responsabilidade cerca dos recursos naturais que são utilizados e a destinação correta desses materiais. Governos, empresas, e pessoas devem ser os grandes responsáveis pela produção e consumo sustentável da sociedade. As empresas devem pensar e ter atitudes sustentáveis, obedecendo as leis e políticas públicas de sustentabilidade (BERTONCELLO et al., 2014).

Falar sobre sustentabilidade é um dos temas mais importantes pois, empresas e corporações objetivam com isso a preservação ambiental. Essa atitude acaba sendo de grande valia na luta pela poluição do ambiente. As principais vantagens relacionadas a preservação do meio ambiente no que se refere à produção industrial e a atividade das empresas e organizações é que, atualmente tantas empresas quanto organizações estão desenvolvendo o pensamento da responsabilidade socioambiental, essas entidades adquiriram atitudes para o enfrentamento dos possíveis impactos ambientais que as suas produções possam vir a causar. Empresas e organizações que levam a sério a sustentabilidade e a preservação ambiental, acabam agindo de forma a não comprometer as gerações futuras e assim adquirem maior credibilidade social demonstrando imagem positivo para as pessoas e sociedade em geral (MA, 2015).

\section{METODOLOGIA}

O presente estudo tratou-se de uma pesquisa em fonte bibliográfica, e pesquisa de opinião, no qual foi aplicado um questionário as pessoas que residem em Brejo Santo (CE). Sendo que essas foram selecionadas por conveniência. Segundo os conceitos de Gil (2010) pesquisa do tipo documental são baseadas em materiais que ainda não forram submetidas a um tratamento analítico ou que porventura podem ser refeitos de acordo com os objetivos estabelecidos segundo cada pesquisador. Já em pesquisas de cunho bibliográfico se faz uso de materiais secundários tais como revistas, jornais, e outros para que haja a produção de novos conhecimentos.

Ressalta-se que o estudo aqui descrito fez uso da pesquisa exploratória. Para Gil (2010), esse tipo de estudo objetiva o esclarecimento de fatores que contribuem para o acontecimento de determinados fenômenos. Foi uma pesquisa aplicada no que concerne a maneira de abordagem da problemática de forma qualitativa através de um questionário. O instrumento de estudo foi baseado na aplicação de um questionário para as pessoas que residem em Brejo Santo (CE). A pesquisa foi feita na cidade de Brejo Santo, localizada ao sul do estado do Ceará. Elas possuem 49.109 habitantes, tendo como destaque para a economia local os setores de indústria e comercio (IBGE, 2019).

Esse questionário foi composto por 12 perguntas fechadas com a indicação de alternativas. Questionários com essas características facilitam a obtenção de informações e permitem a aplicação direta, eliminando a necessidade da realização de classificações aos dados obtidos, são facilmente tabulados com 
auxílios de software simples (NOGUEIRA, 2002). Vale destacar esse estudo não é probabilístico, ou seja, não ocorreu uma prévia determinação acerca da amostra a ser alcançada pelo questionário. Considerou-se nesse estudo, a maneira de como o lixo é descartado e o que os cidadãos pensam sobre a destinação correta dos resíduos sólidos produzidos.

\section{RESULTADOS E DISCUSSÃO}

Após o preenchimento dos questionários, foi possível a obtenção dos seguintes resultados. A amostra do presente estudo foi constituída por 221 indivíduos, dos quais 57,0\% eram do sexo feminino e $43,0 \%$ do sexo masculino. Informações essas visualizadas no gráfico 1. A população investigada foram 126 indivíduos do sexo feminino e 95 indivíduos do sexo masculino.

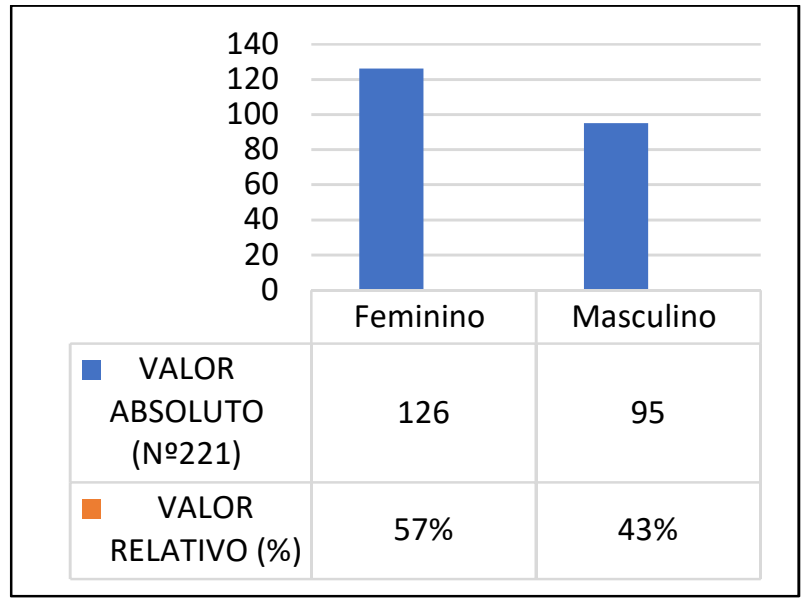

Gráfico 1: Gênero.

Para Krupp (2017), reciclar o lixo, embora seja uma ação fundamental para a proteção ambiental, acaba demandando das pessoas uma conscientização acerca de sua importância exigindo também dos diversos setores da sociedade uma mudança de comportamento no que se refere ao consumo. É notório que se atente ao fato de que o ser humano ao realizar suas atividades quotidianas acabam produzido materiais que se tornarão lixo, levando esses materiais a uma destinação que muitas vezes não é a correta.

Sendo assim, entende-se que não se pode deixar esses materiais se acumularem dentro das residências, ou nas ruas e outros sendo necessário que se faça o descarte desse material de forma correta. No que se refere ao fato de a cidade de Brejo Santo possuir coleta seletiva de lixo, foram obtidas as informações conforme demostrado no gráfico 02: Sempre (50,5\%); quase sempre (27,8\%), Raramente $(10,6 \%)$, Nunca $(9,7 \%)$ e $(0,5 \%)$ relataram que não sabiam se havia ou não esse tipo de coleta em Brejo Santo.

A região de Brejo Santo oferta aos catadores que trabalham na reciclagem e cooperativas de lixo, cursos de capacitação para que os mesmos tenham o conhecimento de quais resíduos podem ser utilizados no processo de reciclagem, além de disponibilizar o aterro sanitário, ainda houve a construção de um lugar adequado para que haja seleção de todo o material que será utilizado no processo de seleção do lixo para a reciclagem. Para Portogente (2016) a coleta seletiva de lixo compreendo uma das atividades extremamente importantes para destinação correta dos resíduos sólidos que são produzidos pela sociedade, além de ser importante acaba representando uma forma de geração de renda para muitas pessoas e para a economia de 
diversas empresas. Também significa uma vantagem para o meio ambiente no que se refere à diminuição da poluição ambiental.

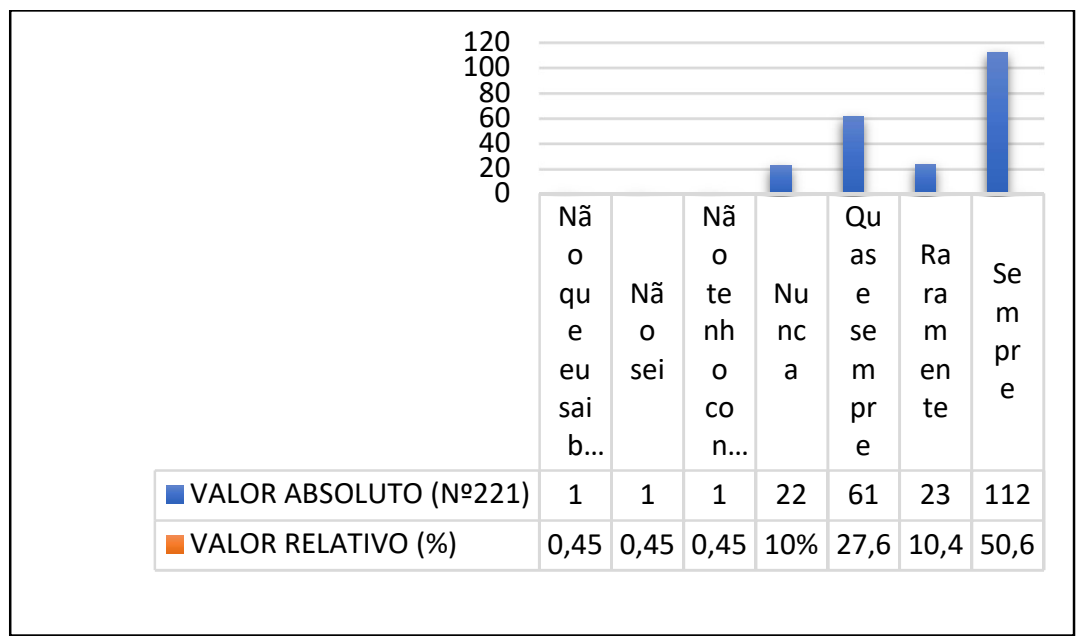

Gráfico 2: Existência de coleta seletiva na cidade.

Conforme o gráfico $03,60,15 \%$ dos indivíduos avaliados responderam que conheciam o trabalho desenvolvido pela cooperativa de catadores de lixo na cidade e que acham de fundamental importância esse tipo de coleta na cidade, pois a mesma estava se desenvolvendo e a população produzia muito lixo e esses se não recebem adequada destinação acabam se acumulando nas ruas e quando chove poderia entupir bueiros e causar prejuízos em época chuvosa.

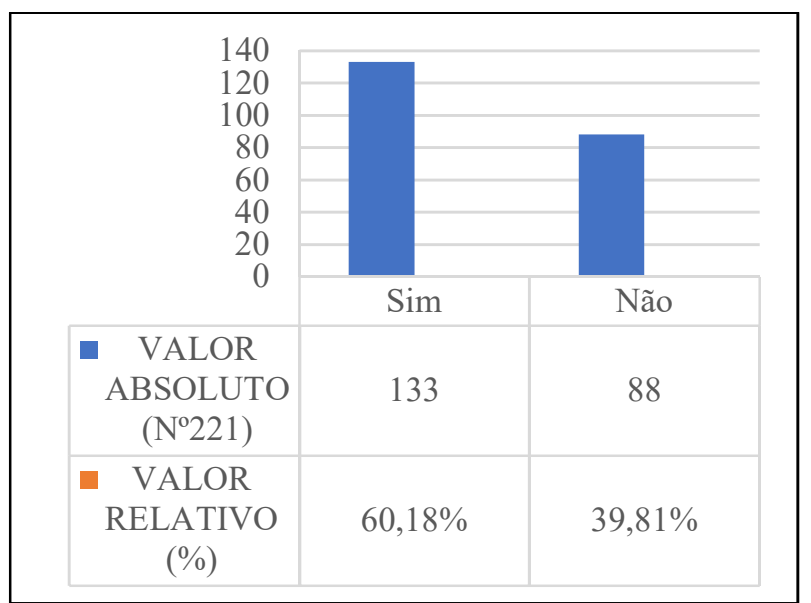

Gráfico 3: Conhecimento da população de Brejo Santo acerca do trabalho da cooperativa (s) de catadores que atuam em parceria com o município, estando incluídas no processo de coleta, triagem e reciclagem.

O advento da Política Nacional de Resíduos Sólidos trouxe para as cidade a ideia de que deveriam abandonar a utilização dos famosos lixões, e pra isso, houve a adoção dos aterros sanitários como alternativas que atuavam para a destinação de todo o lixo que era produzido pelas mesas, sendo que até o ano de 2014 os lixões a céu aberto não deveriam mais existir nessas regiões (MA, 2015)

Questionados sobre a preocupação em relação ao lixo que eram produzidos nas residências, $60,18 \%$ mencionaram que 'sim' se preocupam em fazer a separação do lixo, e que o fazem com frequência, pois muitas vezes há nesses materiais, como por exemplo vidro ou itens que podem ferir o pessoal da coleta de lixo, então sempre seria bom que as pessoas fizessem uma separação sobre todo resíduo sólido que viesse a 
ser descartado para que não provocassem acidentes com o pessoal da limpeza urbana. Já outros relataram que não $(39,81 \%)$ não possuíam o hábito de separar o lixo e nem se atentavam a isso (gráfico 4).

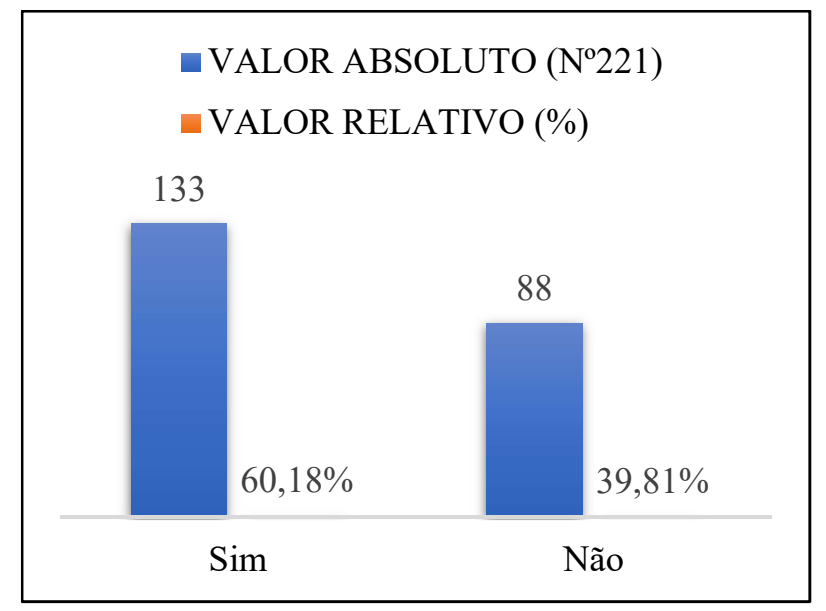

Gráfico 4: Conhece alguma cooperativa (s) de catadores que atuam em parceria com o município, estando incluídas no processo de coleta, triagem e reciclagem?.

Embora muitos não saibam o quanto a coleta seletiva de lixo seja importante e que o processo de coleta seletiva seja fundamental para os indivíduos que veem nesse meio um fonte de renda, o processo de reciclagem de materiais hoje é algo comum na região brejosantese, pois, atualmente, a cidade possui aterro sanitário e entrou para as cidades que aderiram as normatizações da Política Nacional de Resíduos sólidos. Os principais itens que faziam parte do tipo de resíduos gerados nas residências estão discriminados no gráfico 5 . Boa deles eram restos de alimentos $94 \%$, papéis $74,1 \%$ e plásticos $76,7 \%$.

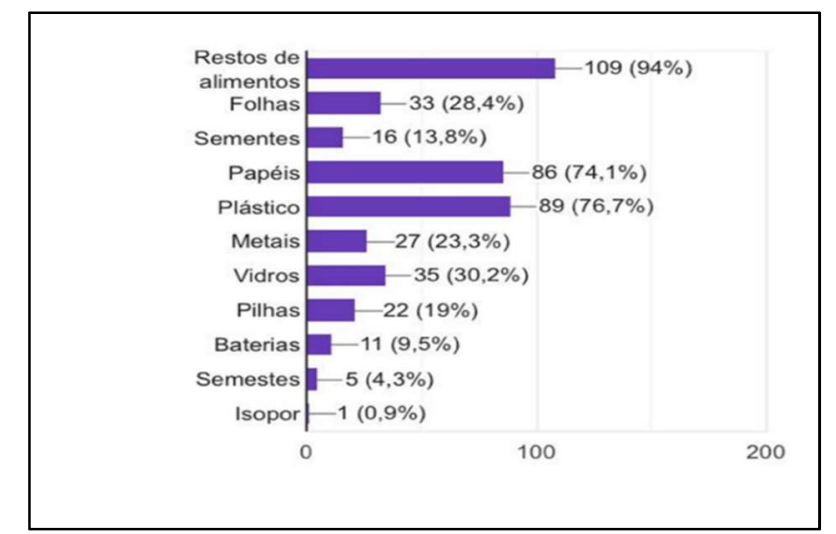

Gráfico 5: Qual tipo de resíduos gerados em sua residência?.

Embora grande parte do lixo produzido pela sociedade possa ser reaproveitados ou reciclados, as pessoas não possuem conscientização acerca de que um dos grandes problemas ocasionados pelo acúmulo de lixo seria a contaminação do meio ambiente bem como doenças ocasionados pelas famosas pragas urbanas (ratos, baratas etc.).

Trabalhar de forma a reeducar a sociedade acerca de conceitos relacionados ao processo de descarte adequado dos resíduos sólidos é uma das atividades fundamentais mediante a necessidade se conscientizar sobre o consumismo (MENDONÇA et al., 2017). Questionados sobre o fato de separarem ou não o lixo por tipo, $66,00 \%$ dos indivíduos entrevistados disseram que não e 34,00\% relataram que sim, fazem a separação 
do lixo por tipo de material. As principais destinações que o lixo recebia podem ser vistos no gráfico 7. É notório observar que a principal destinação relatada pelos indivíduos foi 'lixo comum'.

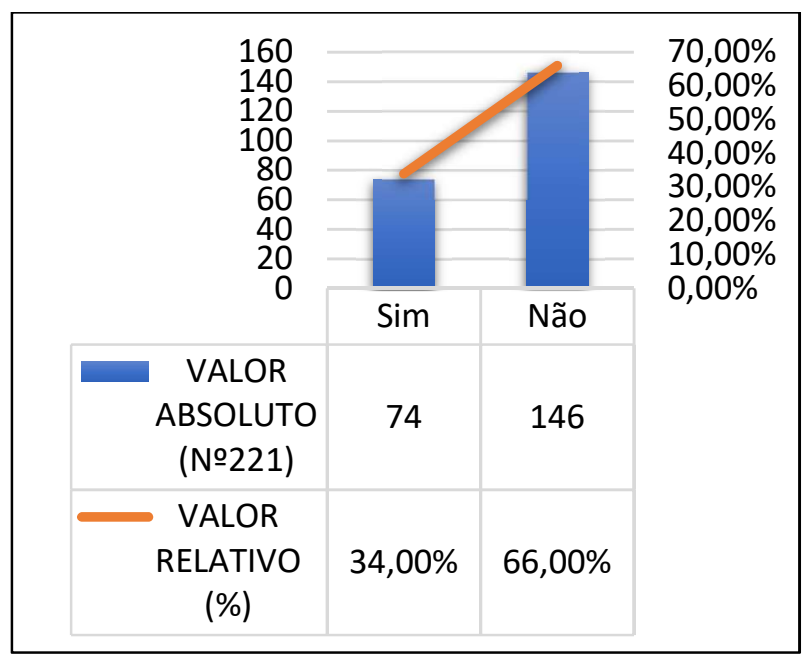

Gráfico 6: Você separa esses resíduos por tipos?.

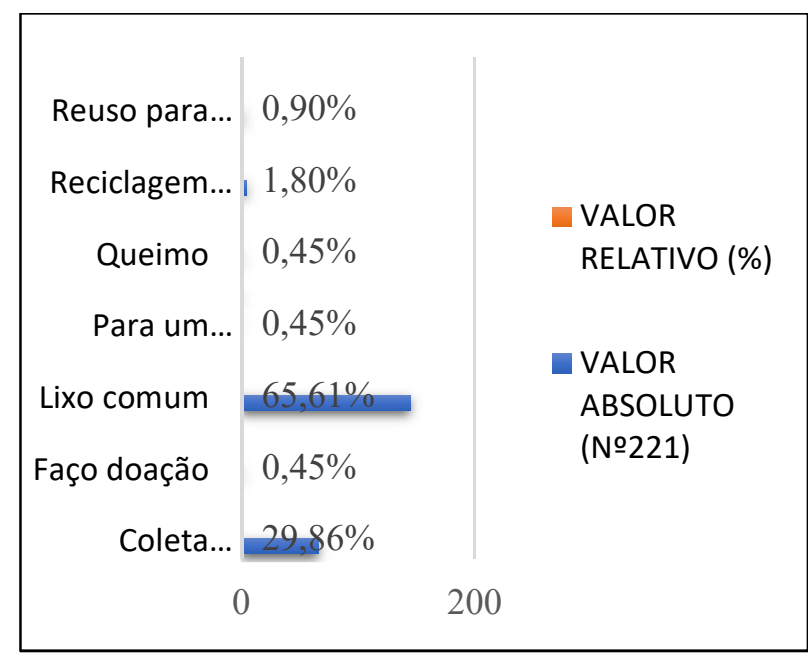

Gráfico 7: Qual a destinação dada a esses resíduos?

Para Guarnieri (2013), através da Logística Reversa, as instituições empresariais podem se beneficiar pois a partir disso acabam obtendo diminuição de custos devido ao desperdício, reciclagem de materiais, reaproveitamento desses e redução de multas devido a poluição ambiental; se beneficiam também devido ao aumento das receitas de produtos ecologicamente corretos, demonstram um perfil positivo em relação a imagem institucional da empresa e consequentemente conquistam novos mercados.

Questionados sobre o fato de se beneficiarem ou não através da coleta seletiva do lixo, boa parte dos entrevistados responderam que sim $(65,16 \%)$ através da produção de sabão advindo de material que já tinha sido usado e que agora recebeu uma nova destinação, outros já disseram que se beneficiaram através da produção de brinquedos ou materiais de garrafa pet ou que vendiam esses materiais advindo do processo de coleta seletiva para as empresas que atuam nesse ramo. Já 34,84\% disseram não se beneficiam com a coleta seletiva de lixo (gráfico 8).

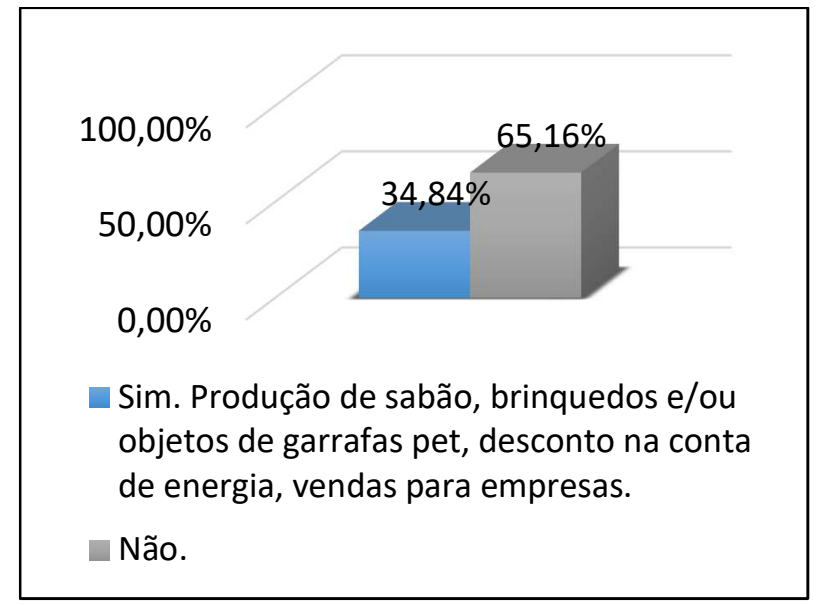

Gráfico 8: Já se beneficiou de algum processo de coleta seletiva? Se sim, como? Outros. Qual?.

Leite (2012) menciona que a prática de ações voltadas a Logística Reversa e a destinação correta dos resíduos sólidos produzidos pelo homem, acaba sendo uma ferramenta fundamental e promissora para a área empresarial e social, principalmente no que concerne ao fato de que atualmente as empresas buscam 
um relacionamento harmônico entre economia e meio ambiente. Sendo de grande importância o consumo inteligente, no qual tanto consumidores como fornecedores desempenhem seus papeis de forma a não contribuir para a poluição ambiental. Sobre o fato de que a Logística reversa de resíduos sólidos domésticos era uma oportunidade empreendedora, 44,34\% responderam sim; 51,58\% disseram não, 3,16\% mencionaram que talvez; $0,45 \%$ relataram que as vezes e $0,45 \%$ falaram acho que sim. Dados esses mostrados no gráfico 9.

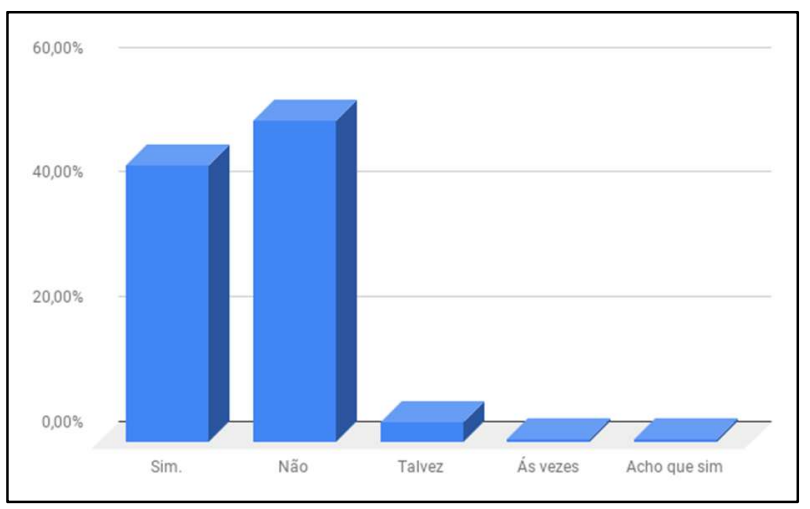

Gráfico 9: Você ver a Logística reversa de resíduos sólidos domésticos como sua oportunidade empreendedora? Como?.

De acordo com Fonseca, (2015) nos últimos tempos percebeu-se que há uma intensa preocupação com questões relacionadas ao meio ambiente, esses questionamentos se veem de forma conjunta ao uso racional dos recursos ecológicos utilizados pelo homem moderno. Em razão disso é que boa parte das ações desempenhadas pela logística reversa tem ganhado aliados entre os ambientes empresariais e entre os indivíduos que fazem o uso racional da matéria prima e dos diversos produtos que fazem parte desse 'mundo' de reaproveitamento de materiais que foram consumidos.

Segundo análise dos indivíduos avaliados, e de acordo com as respostas obtidas mediante os questionamentos abordados no questionário utilizados para a coleta de informações sobre a temática debatida no presente estudo, a tabela 1 representa de forma resumida como a logística reversa é entendida pelos indivíduos entrevistados.

Tabela 1: Como a Logística reversa de resíduos sólidos domésticos é vista segundo os entrevistados.

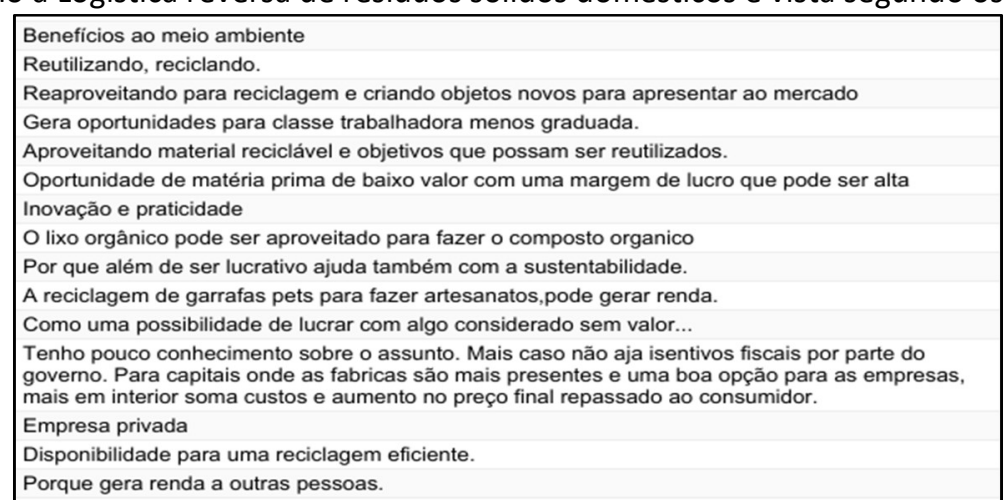

A criação de políticas direcionadas ao descarte correto e a reciclagem de materiais, passam a fazer parte de medidas adotadas pelas empresas, e de forma estratégica está sendo uma ação realizada de maneira 
a melhorar a imagem de responsabilidade socioambiental que elas veem promovendo. Através dessa prática, todos os produtos comercializados que já foram utilizados, perfazem um novo caminho podendo esses serem retirados ou receberem descartes adequados de forma a não poluir o meio ambiente, conceitos esses também abordados por Soares (2016) e Bassani et al. (2016).

Mendonça et al. (2017) e Souza, (2018) acabam nos revelando que a Logística Reversa está diretamente correlacionada com a maneira de se destinar os materiais e produtos que já passaram pelo uso final e que porventura serão descartados. Sendo uma maneira de atuar no incentivo ao consumidor, na produção de ações que podem contribuir de forma positiva na diminuição de novos resíduos e uma preocupação acerca desses materiais quando são lançados no meio ambiente.

Dessa forma é fundamental dizer que empresas e sociedades devem estar atentas quanto ao uso correto dos recursos que são ofertados pela natureza, pois essa é uma característica que também se associa ao fato de que se a sociedade e as áreas empresariais não se sensibilizarem diante da possibilidade de desequilíbrio ambiental, esses acabarão contribuindo para prejudicar a homeostase da vida de todos os seres vivos que habitam o planeta terra.

\section{CONSIDERAÇÕES FINAIS}

Conclui-se que a temática sobre Logística Reversa se tornou uma ideia bastante difundida no meio da sociedade moderna, ganhando cada vez mais destaque entre as novas concepções acerca do consumo inteligente. Hoje a mesma se direciona a um ambiente competitivo sustentável em relação a concorrência no mundo dos negócios, fazendo com que a valorização do ciclo de vida dos produtos consumidos pela sociedade em geral e a busca constante pelo desenvolvimento sustentável tornem-se um dos pilares responsáveis por fazer da logística reversa uma iniciativa positiva tanto para as empresas quanto para os consumidores. Partindo dessas concepções, entende-se então que falar de logística reversa é fundamental tanto para as empresas quanto para a sociedade, principalmente no que se relacionada ao objetivo de manter um relacionamento de harmônico entre indivíduos, meio ambiente e empresas.

A atenção dada aos resíduos que são produzidos pela sociedade no último tempo tem sofrido muitas modificações. Hoje é comum que as pessoas separem seus lixos e tenham todo cuidado para destiná-los da forma correta, bem como também fazem uso de produtos adivinhos da reciclagem e estejam conscientes acerca da importância da destinação correta dos resíduos sólidos por eles produzidos. É notório que há diversas pessoas que valorizam esse tipo de comportamento, mas há também uma pequena parcela que apesar de terem conhecimento acerca da importância da reciclagem dos materiais e da destinação correta do lixo ainda se comportam de maneira contrária a isso.

A sociedade constantemente produz toneladas de resíduos sólidos. Como atuar diante desse comportamento de forma contribuir para não poluir o meio ambiente? Uma das respostas obtidas no presente estudo foi o fato desse, trabalhar a reeducação referente a esse tema e incentivar a sociedade em geral a direcionar o seu olhar para práticas de sustentabilidade e preservação ambiental. 


\section{REFERÊNCIAS}

ALMEIDA, K. M. V.. Logística reversa para gestão de resíduos e coprodutos da cadeia de biodiesel: estudo de caso em usinas do nordeste brasileiro. Tese (Doutorado em Engenharia Civil) - Universidade Federal de Pernambuco, Recife, 2012.

BASSANI, M. F.; MACKE, J.. A logística reversa e a responsabilidade social nas empresas. Revista de Administração e Comércio Exterior, v.2, n.1, p.61-74, 2016.

BERTONCELLO, S. L. T; CHANG JÚNIOR, J.. A importância da Responsabilidade Social Corporativa como fator de diferenciação. Responsabilidade Social, n.183, 2014.

BRASIL. Ministério do Meio Ambiente. Gestão Integrada dos Resíduos Sólidos. Brasília: MMA, 2016.

DIAS, S. M. F.. Proposição de uma matriz de indicadores de sustentabilidade em gestão integrada de resíduos sólidos urbanos e sua aplicação em um estudo de caso. Feira de Santana: UEFS, 2009.

EON, F.. O que é responsabilidade social. Responsabilidade Social, n.200, 2014.

FONSECA, E. C. C.. Evolução dos estudos de logística reversa realizados no Contexto nacional: uma análise bibliométrica. Produção Online, Florianópolis, v.15, n.4, p.1457-1480, 2015.

GONÇALVES, P.. A cultura do supérfluo: lixo e desperdício na sociedade de consumo. Rio de Janeiro: Garamond, 2011.

GUARNIERI, P.. A mensuração dos efeitos financeiros e econômicos da logística reversa pela contabilidade ambiental. Meio Ambiente e Sustentabilidade, v.3, n.2, 2013.

GUARNIERI, P.. Logística reversa: em busca do equilíbrio econômico e ambiental. Recife: Clube de Autores, 2011. IBGE. Instituto Brasileiro de Geografia e Estatística. Brejo Santo. Rio de Janeiro: IBGE, 2019.

ISIDRO, A. S.. Análise da logística reversa, uma alternativa de criação de valor para o cliente: um estudo de caso da Natal Reciclagem. Monografia (Graduação em Administração) - Universidade Federal do Rio Grande do Norte, Natal, 2013.

KRUPP, R.. A Logística reversa de pós-consumo: um estudo de caso na Cooperativa Cootre de Esteio-RS. Revista de Gestão Ambiental e Sustentabilidade, v.6, n.1, p.72-86, 2017.

LEITE, P. R.. Direcionadores estratégicos em programas de logística reversa no Brasil. Alcance, v.19, n.2, p.182-201, 2012.
LEITE, P. R.. Direcionadores estratégicos em programas de logística reversa no Brasil. Alcance, v.19, n.2, p.182-201, 2012.

LEITE, P. R.. Logística Reversa: Meio Ambiente e Competitividade. 2 ed. São Paulo: Pearson Education, 2009.

MA. Marketing Ausland. A importância da responsabilidade socioambiental nas empresas. Curitiba: MA, 2015.

MAURER, A. L.. As Gerações Y e Z e suas âncoras de carreira: contribuições para a gestão estratégica de operações. Dissertação (Mestrado em Administração) Universidade de Santa Cruz do Sul, Santa Cruz do Sul, 2013.

MCWILLIAMS, A.; SIEGEL, D.. Corporate Social Responsibility: A theory of the Firm Perspective. Academy of Management Review, v.26, n.1, p.117-127, 2002.

MELO, M. F.; MELO, A. Z.. Uma análise das práticas de Responsabilidade Social e Sustentabilidade como estratégias de empresas industriais do setor moveleiro: um estudo de caso. Gestão e Produção, v.25, n.1, p.81-93, 2018.

MENDONÇA, J. C. A.. Logística reversa no Brasil: um estudo sobre o Mecanismo ambiental, a responsabilidade social corporativa e as legislações pertinentes. Capital Científico, v.15, n.2, 2017.

NOGUEIRA, R.. Elaboração e Análise de Questionários: Uma Revisão da Literatura Básica e a Aplicação dos Conceitos a um Caso Real. Rio de Janeiro: UFRJ, 2002.

PEREIRA, A. L.. Logística reversa e sustentabilidade. São Paulo: Cengage Learning, 2012.

PORTER, M. E.. Estratégia Competitiva: Técnicas para análise de indústrias e da concorrência. 18 ed. São Paulo: Campus, 1986.

PORTOGENTE. Portal Portogente. Logística Reversa de PósConsumo. Santos: Portal Portogente, 2016

RIBEIRO, D.. Sustentabilidade: Formas de Reaproveitar os Resíduos da Construção Civil. Revista de Ciências Gerenciais, v.20, n.31, p.41-45, 2016.

SHIBAO, F. Y.. A logística reversa e a sustentabilidade empresarial. Seminários em administração, v.13, 2010.

SOARES, I. T. D.. Logística reversa: uma análise de artigos publicados na base SPELL. Revista de Gestão Ambiental e Sustentabilidade, v.5, n.2, p.77-97, 2016.

SOUZA, C. O. A.. A importância da logística reversa para a obtenção de vantagem competitiva entre as organizações e a contribuição para preservação do meio ambiente. Monografia (Especialização em Gestão em Logística) - Centro Universitário de Brasília, Brasília, 2018.

A CBPC - Companhia Brasileira de Produção Científica (CNPJ: 11.221.422/0001-03) detém os direitos materiais desta publicação. Os direitos referem-se à publicação do trabalho em qualquer parte do mundo, incluindo os direitos às renovações, expansões e disseminações da contribuição, bem como outros direitos subsidiários. Todos os trabalhos publicados eletronicamente poderão posteriormente ser publicados em coletâneas impressas sob coordenação da Sustenere Publishing, da Companhia Brasileira de Produção Científica e seus parceiros autorizados. Os (as) autores (as) preservam os direitos autorais, mas não têm permissão para a publicação da contribuição em outro meio, impresso ou digital, em português ou em tradução. 